\title{
La proposta educativa de l'Escola del Consum de Catalunya per treballar l'educació del consum i l'educació científica
}

\author{
Josep Bonil, Genina Calafell, Marta Fonolleda i Maia Querol \\ Escola Catalana del Consum (Agència Catalana del Consum) i Dep. Didàctica de la Matemàtica i de les C. \\ Experimentals (UAB) \\ josep.bonil@uab.es
}

Es presenta un taller ofert per l'Escola del Consum de Catalunya que aborda el fenomen dels berenars des d'una perspectiva oberta i complexa a partir del diàleg entre l'educació del consum i l'educació científica. En aquest taller s'aposta per la creació d'escenaris didàctics creatius, incorporant-hi diversitat de llenguatges.

Paraules clau: educació del consum, educació científica, model ésser viu, complexitat

\begin{abstract}
El Menjamí és un home de negocis que ha decidit obrir un restaurant de berenars al barri... però no li entren clients. En la seva carta ofereix berenars com una suculenta sopa de peix, un entrepà d'escalivada i un pastís de truites variades. A la sortida de l'escola, us sorprèn el Menjamí i us convida al seu restaurant...

Nyam, nyam... què hi a per berenar?
\end{abstract}

En Menjamí és un personatge que introdueix el fenomen de la salut $i$ els estils de vida als tallers que l'Escola del Consum de Catalunya ofereix a l'alumnat de cicle inicial d'Educació Primària per treballar l'educació del consum incorporant continguts del currículum de l'etapa.

\section{QUĖ ÉS L'ESCOLA DEL CONSUM DE CATALUNYA?}

L'Escola del Consum de Catalunya (ECC) de l'Agència Catalana del Consum és un servei públic gratuït que vol afavorir i potenciar la presència de l'educació del consum a l'àmbit educatiu català. Aposta per una interacció entre activitat docent, innovació metodològica i recerca en aspectes de consum. És per aquest motiu que es configura com un Centre d'Estudis de l'Educació del Consum.

Apostant per l'equitat territorial, l'ECC disposa de dos àmbits de funcionament paral-lels i complementaris: una seu central situada a la ciutat de Barcelona i una seu territorial que es desplaça per tot el territori català.

D'ençà de la seva creació, l'ECC ha anat definint i consolidant una oferta educativa i una línia pròpia d'entendre l'Educació del Consum que configura la seva identitat. L'Escola del Consum de Catalunya ofereix un espai complet per realitzar-hi activitats que permeten a l'alumnat reflexionar i aprofundir sobre diferents temàtiques relacionades amb els actes quotidians de consum. L'oferta educativa de l'ECC es centra sobretot en la proposta d'activitats per als alumnes de Primària, Secundària, Batxillerat, Cicles Formatius i Educació Especial.

L'oferta educativa de tallers de l'ECC segueix una organització diferent segons que es dirigeixi a l'alumnat d'Educació Primària, d'Educació Secundària, Batxillerats, Cicles Formatius o Educació Especial. D'aquesta manera l'ECC aposta per diversificar les dinàmiques, els continguts i l'estructura, així com la durada de l'activitat segons les característiques de l'alumnat que hi participa. Per aquest motiu els tallers per a l'alumnat de secundària es desenvolupen en una franja horària de tres hores al 
llarg d'un matí. Els tallers per a l'alumnat de primària, en una franja de 90 minuts. I els tallers per a alumnat amb necessitats educatives especials, en un interval de temps de dues hores.

Per realitzar la reserva d'una visita els centres educatius han de sol-licitar-la a la pàgina web de I'ECC (www.consum.cat) i escollir els tallers que més s'adeqüen a les seves necessitats.

\section{PLANTEJAR UNA EDUCACIÓ DEL CONSUM QUE INTEGRI L'EDUCACIÓ CIENTÍFICA}

Des de l'ECC, es considera que els tallers que s'ofereixen són una oportunitat per incorporar els diferents continguts curriculars des d'una enfocament que afavoreixi la presència de l'educació del consum en el currículum educatiu. Per això, el referent que orienta el disseny de les activitats és el currículum de les diferents etapes del sistema educatiu català. En el cas de l'exemple que es presenta a continuació, el contingut científic de referència és el cos humà a Cicle Inicial de l'etapa d'Educació Primària.

El taller Nyam, nyam.. què hi ha per berenar? pren com a punt de partida el fet quotidià de berenar que es presenta com un flux de matèria (menjar, begudes...) que entra dins el cos. Des d'aquesta perspectiva, el berenar es connecta amb un procés de transformació de la matèria i l'energia que entra i surt d'un ésser viu. Al mateix temps, el berenar es vincula amb la funció de nutrició dels éssers vius, ja que l'alumnat reflexiona entorn a la di- versitat de berenars, les propietats dels aliments i la seva relació amb el metabolisme del propi cos. El taller planteja com les propietats dels aliments es vinculen a la funció de nutrició entenent que hi ha berenars com la fruita que aporten vitamines necessàries perquè els infants puguin nodrir-se i créixer o que la llet aporta el calci necessari per a enfortir els ossos.

També es treballa com un berenar pot decidirse en funció d'un context i les activitats que s'hi desenvolupen. En aquest cas, es planteja a l'alumnat com la realització d'una activitat esportiva, un passeig o jugar amb els amics són activitats que requereixen una aportació d'aliments diferents, i com els éssers vius regulen l'entrada i la sortida d'aliments i la seva transformació en funció de les característiques del medi i de les seves necessitats.

El taller pren com a referència l'individu i treballa com la identitat i les característiques de les persones condiciona la quantitat i les propietats dels aliments que s'ingereixen. Es treballa com l'alimentació d'una persona pot anar canviant al llarg del seu creixement ja que en cada etapa evolutiva hi poden haver necessitats i característiques diferents. En l'activitat plantejada aquest fet es concreta en la reflexió entorn a com és el berenar d'un infant d'un any, d'un nen o nena de 6 anys, d'un persona adulta com el pare o la mare o d'una persona gran com els avis. A partir de la qual es reflexiona en com el berenar malgrat mantenir uns trets i unes propietats identitàries també va canviant al llarg del temps.

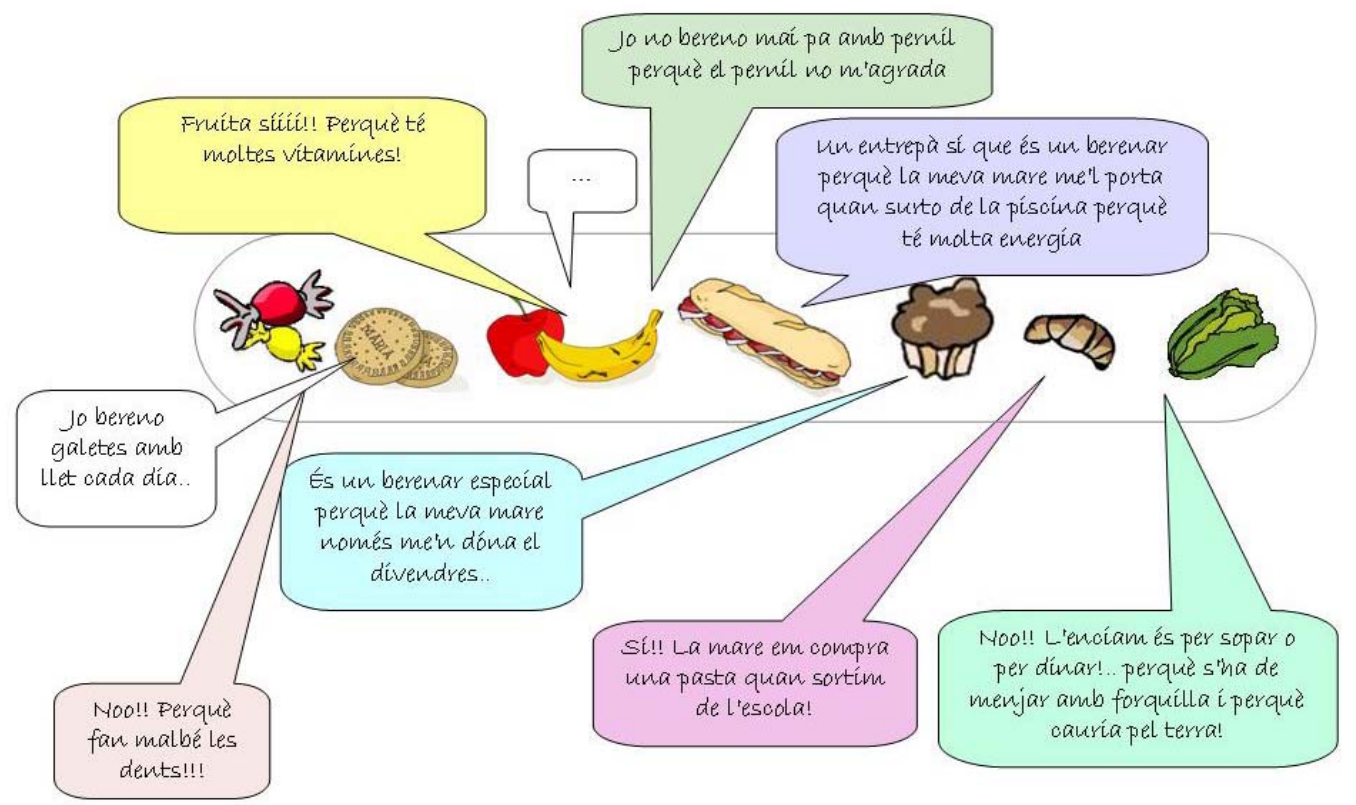

Figura 1. Exemple de l'activitat d'introducció del taller Nyam, nyam... què hi ha per berenar? 


\section{Un cas pràctic: el taller Nyam, nyam... què hi ha per berenar?}

El restaurant "Mitja tarda" té una característica molt especial: les comandes s'hi realitzen mitjançant l'expressió corporal $i$ el moviment del cos. Sort que la Joana Poca Gana, una bona amiga d'en Menjamí, l'ha acompanyat fins a l'aula per a poder ajudar-nos a investigar en aquest llenguatge. Sabríeu demanar un entrepà de pernil dolç i una taronjada per mitjà del moviment del vostre cos?

El punt de partida de l' activitat és l'escenificació dels personatges d'en Menjamí i la Joana Poca Gana. Una activitat que utilitza la teatralització i l'expressió corporal per a plantejar a l'alumnat una situació que hauran de resoldre al llarg del desenvolupament del taller. Una situació que connecta amb la pregunta que presenta el fenomen i el taller: Nyam, nyam... què hi ha per berenar?

A partir d'aquest escenari d'aula es promou un diàleg entre els participants entorn de la identitat del berenar. L'ús de diverses imatges permet a l'alumnat intercanviar punts de vista i construir conjuntament els criteris que els hi són significatius per identificar un berenar (fig.1).

\section{Tothom berena de la mateixa manera?}

Seguidament i com a segona activitat es planteja la pregunta: Tothom berena de la mateixa manera? Una qüestió que planteja la diversitat de factors que intervenen a l'hora de decidir un berenar.

Per a concretar aquests continguts a l'aula es distribueix l'alumnat en grups de treball i es reparteix un full d'activitats on l'objectiu és relacionar contextos, persones, tipus de berenars i propietats dels aliments, fent èmfasi perquè l'alumnat justifiqui les relacions establertes (fig. 2).

Seguidament es realitza una posada en comú amb tot el grup classe que permet identificar com hi ha diversitat de relacions i possibilitats a l'hora de plantejar un berenar. Una dinàmica que permet enriquir el treball en grups reduïts a partir de les aportacions col-lectives. Obrint el diàleg a noves situacions, persones o aliments que podrien intervenir.

\section{Què necessitem per berenar?}

A continuació es planteja una nova pregunta: Què necessitem per berenar? És per treballar els

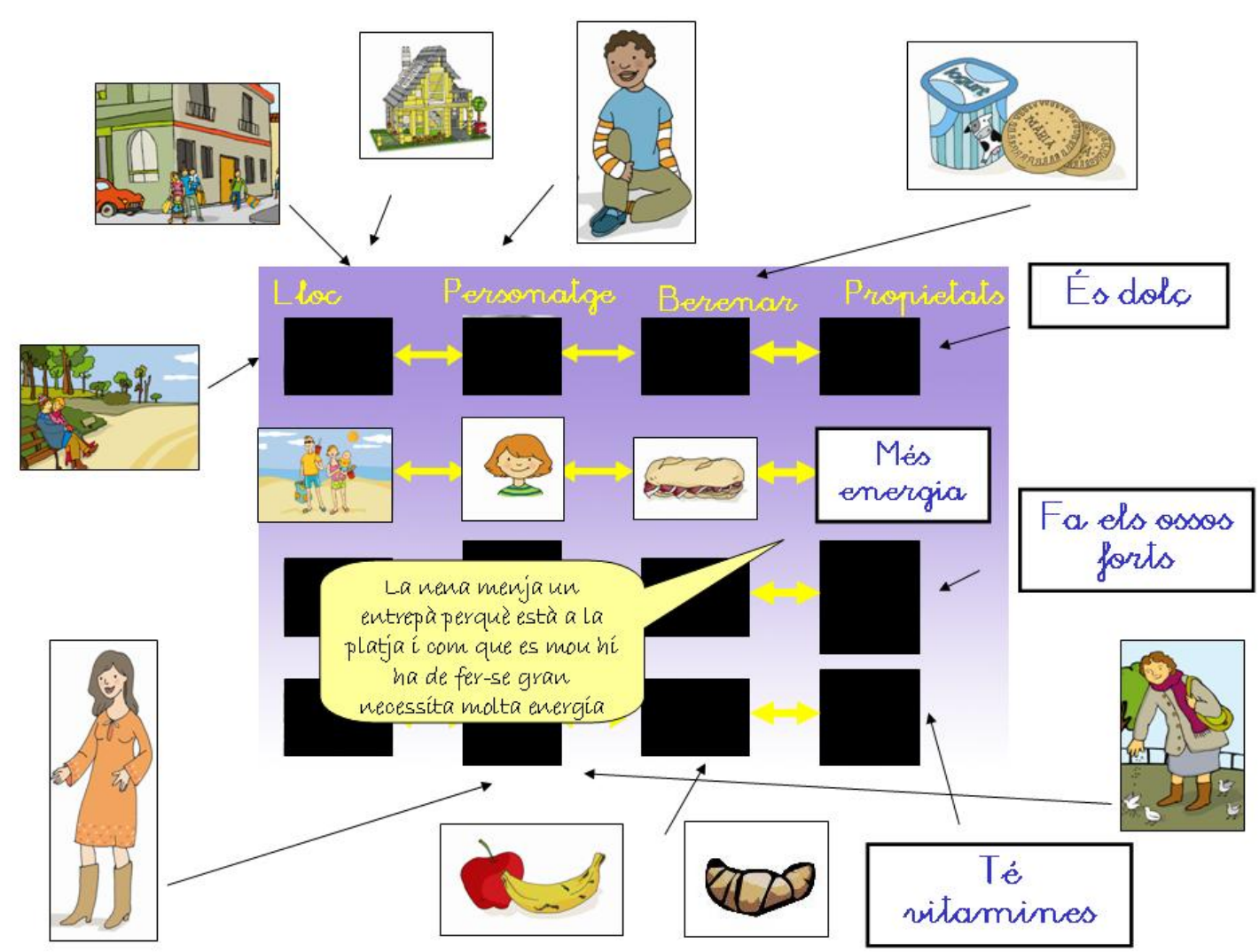

Figura 2. Exemple de l'activitat Tothom berena de la mateixa manera? 
diferents elements que intervenen a l'hora de preparar un berenar focalitzant en aspectes propis del consum. Els infants treballen com el berenar és un acte quotidià de consum en el que intervenen diversitat d'elements que esdevenen fluxos materials com els productes alimentaris necessaris per a preparar un berenar o l'existència d'un establiment on comprar els productes, o fluxos de diners. També com el berenar interacciona amb un context social (el berenar a una festa d'aniversari, el berenar que està de moda...) o un marc legislatiu (tiquet, preu total...). En definitiva es treballa el berenar com a resultat d'un intercanvi.

Per plantejar aquests continguts es reparteix entre l'alumnat un full d'activitats amb diferents elements que es poden considerar necessaris per obtenir un berenar, deixant un espai en blanc perquè l'alumnat pugui complementar-ho amb nous elements que consideri significatius. Cada infant del grup de treball negocia i justifica el seu punt de vista per tal de consensuar entre tots els tres elements que consideren prioritaris (fig. 3).
A continuació, seguint la dinàmica de l'activitat anterior es realitza una posada en comú per identificar conjuntament els elements necessaris que intervenen en el procés de compra d'un berenar o de compra dels aliments necessaris per preparar un berenar.

Ara que en Menjamí ja sap millor quins productes pot oferir com a berenars en els seu restaurant... voleu anar-hi a berenar? Tanqueu els ulls

i escolteu... són les cinc de la tarda, acabeu de sortir de l'escola i amb la vostra família passegeu cap a casa quan de cop $i$ volta... Han obert un restaurant nou a la cantonada de l'Escola... Mireu pels vidres i... sí, sí... és ell! És el restaurant del vostre amic Menjamí! I també hi ha la Joana pocagana! Animeu a tota la família a entrar-hi... Nyam, nyam... què hi a per berenar?

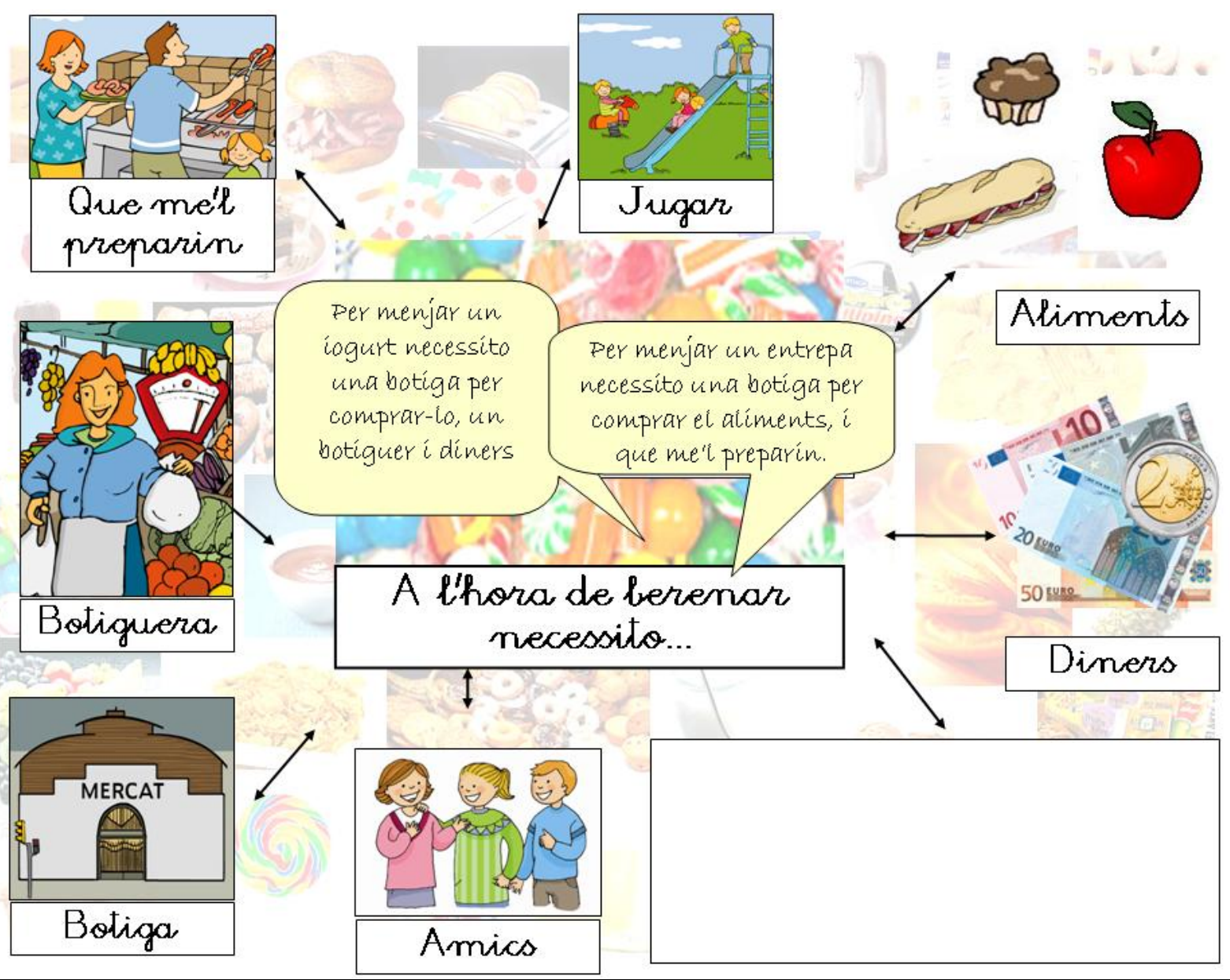

Figura 3. Exemple de l'activitat Què necessitem per berenar? 


\section{L'activitat final}

Per finalitzar el taller es proposa una activitat que posa en joc els continguts treballats al llarg del taller connectant-los amb l'activitat inicial d'escenificació dels personatges i la formulació de la pregunta del taller: Nyam, nyam... què hi ha per berenar?

L'activitat proposada és la preparació d'una comanda per berenar en el restaurant "Mitja tarda" d'en Menjamí. Es proposa a l'alumnat que planifiqui una comanda considerant el context, les característiques i els gustos de les persones, l'establiment, els productes necessaris, els diners... Per facilitar la connexió entre el treball proposat i l'escenari didàctic creat a l'aula s'utilitza el llenguatge corporal. L'alumnat a partir d'unes orientacions investiga en el moviment del seu cos per entrar al restaurant d'en Menjamí i demanar la seva comanda. Utilitzant diversitat de moviments expressa el procés de compra i el tipus d'aliments que berenaran.

La introducció de l'expressió corporal en el taller permet contemplar altres continguts curriculars de l'etapa primària afavorint que l'alumnat representi i comuniqui el seu procés d'aprenentatge al llarg del taller per mitja del llenguatge corporal.

En grups de treball l'alumnat planifica un berenar segons els criteris treballats al llarg del taller i amb uns condicionants que s'assignen a l'atzar. Per exemple, un grup d'alumnes després d'haver llegit la carta de berenars del restaurant d'en Menjamí, tenint en compte els diners que tenen i que acaben de sortir de la piscina poden decidir berenar un entrepà de formatge $i$ un batut. Per aquest motiu l'alumnat decideix moure's amb uns grans salts per expressar que és un berenar molt energètic.

Un cop cada grup ha decidit el seu berenar i la seva representació amb el cos, es teatralitza l'entrada de cada grup al restaurant d'en Benjamí. De forma que també s'utilitza el treball realitzat amb el llenguatge corporal per seqüenciar el procés de compra: salutació, demanda del producte -en aquest cas el berenar-, pagament amb diners, compra del berenar i retorn del tiquet i el canvi per part d'en Benjamí.

\section{ALGUNES CONCLUSIONS...}

La relació entre la salut i els estils de vida es converteix en una oportunitat per dialogar entre diversitat de sabers que permeten aproximar-se al fenomen des d'una perspectiva oberta i complexa. Una visió en la que el fenomen es construeix des d'una relació entre els models disciplinars, la quotidianitat i significació de l'alumnat i la rellevància per a la societat.

La salut $\mathrm{i}$ els estils de vida esdevenen un punt de partida per treballar amb l'alumnat competències d'educació per a la ciutadania incorporant-hi continguts científics (model ésser viu) i continguts d'altres àrees curriculars des d'un enfocament afavoridor de la presència de l'educació del consum. Un escenari on l'educació científica i l'educació del consum comparteixen i enriqueixen el fenomen per promoure en l'alumnat competències per a pensar, comunicar i actuar com a ciutadans.

La proposta didàctica de l'Escola del Consum posa èmfasi en com s'activen o no les diferents perspectives dels fenòmens del món en funció d'un context o d'una situació concreta.

Una idea que es vincula amb la creació d'escenaris didàctics creatius que es construeixen incorporant diversitat de llenguatges.

Uns espais on prenen força les diferents formes de comunicació, posant en joc la imaginació i la quotidianitat de l'alumnat per tal de desenvoluparlos competències per intervenir com a ciutadà creatiu, actiu i estratègic.

\section{BIBLIOGRAFIA}

Bonil, J. (2008). Educación del Consumo: Nuevas oportunidades. Cuadernos de Pedagogía, 383, 48-51.

Calafell, G., Fonolleda, M., \& Querol, M. (2008). Propuestas para llegar al currículo. Cuadernos de Pedagogía, 383, 52-55.

Pujol, R. M. (2007). Didáctica de las ciencias en la educación primaria. Madrid: Sintesis Educación. 